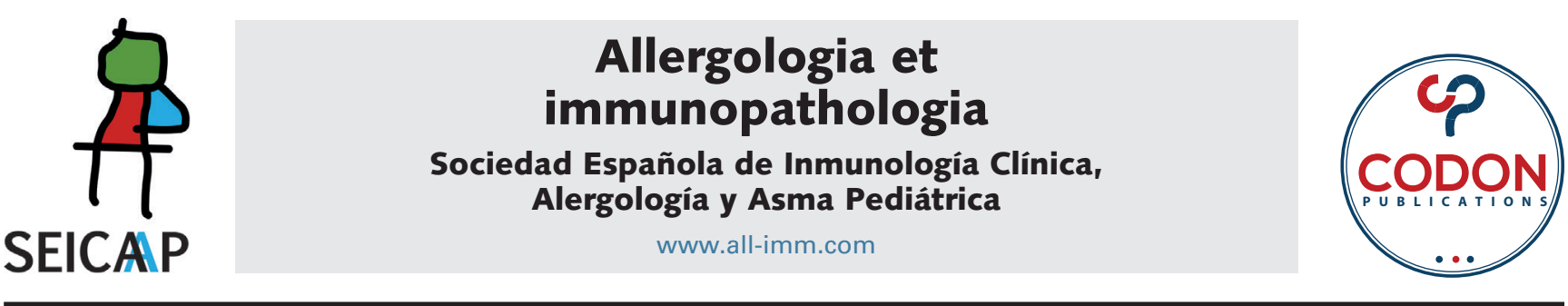

ORIGINAL ARTICLE

\title{
Childhood wheezing phenotypes and their association to perinatal factors: a longitudinal study
}

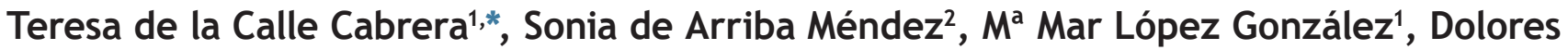 \\ García García', Luis García-Marcos ${ }^{3}$, Purificación Vicente Galindo ${ }^{4}$, Javier Pellegrini \\ Belinchón ${ }^{5}$
}

\author{
${ }^{1}$ Gerencia de Atención Primaria de Salamanca, C.S.Tamames, Salamanca \\ ${ }^{2}$ Sección de Alergia Infantil e Inmunología Clínica, Hospital Universitario de Salamanca \\ ${ }^{3}$ Departamento de Pediatría, Universidad de Murcia \\ ${ }^{4}$ Departamento de Estadística, Universidad de Salamanca \\ ${ }^{5}$ Departamento de Pediatría, Universidad de Salamanca
}

Received 25 October 2020; Accepted 3 February 2021

Available online 1 May 2021

\section{KEYWORDS \\ wheezing; \\ phenotypes; \\ risk factors; \\ children; \\ asthma}

\begin{abstract}
Introduction: Multiple gestational and early life factors have been described as the variables that increase the risk for each phenotype of infantile wheezing. Our objective was to study the evolution of wheezing in a cohort of children followed up to 9-10 years of age and its relationship with different perinatal risk factors.

Methods: A longitudinal study was made on the evolution of wheezing, over time, in 1164 children from Salamanca (Spain) included in the International Study of Wheezing in Infants, when the children were 12 months old. They were classified into three phenotypes: transient early wheezing (last episode before 3 years of age), early persistent wheezing (start before 3 years age and persisting thereafter), and late-onset wheezing (first episode after 3 years of age). Univariate and multivariable analyses were performed to establish associations between the different phenotypes and perinatal factors.

Results: Data were obtained corresponding to a total of 531 children. Of these, 169 (31.8\%) had experienced transient early wheezing, 100 (18.8\%) early persistent wheezing, 28 (5.3\%) late-onset wheezing, and 234 (44.1\%) had never experienced wheezing. Cesarean delivery, early exposure to infections, the presence of atopic eczema, and a smoking father were associated with transient early wheezing. Early persistent wheezing was associated with a family history of allergy, smoking, and obstetric diseases. Exclusive breastfeeding was identified as a protective factor in both transient and persistent early wheezing. Late-onset wheezing was associated with the male gender and with maternal history of rhinitis and eczema.

Conclusions: Wheezing phenotypes were associated with different risk perinatal factors. Knowledge in the field is essential in order to influence the modifiable factors.

(c) 2021 Codon Publications. Published by Codon Publications.
\end{abstract}

*Corresponding author: Teresa de la Calle Cabrera. Pediatrician, Gerencia de Atención Primaria de Salamanca, Centro de Salud de Tamames, Plaza del Ferial s/n. CP 37600 Tamames, Salamanca. E-mail address: delacalleteresa@gmail.com 


\section{Introduction}

Childhood wheezing is extremely common, particularly in the first years of life..$^{1,2}$ However, although wheezing is closely associated with asthma, it is very nonspecific. The prevalence of childhood wheezing and asthma has not been clearly established, though large epidemiological studies such as the International Study of Asthma and Allergies in Children (ISAAC) and the International Study of Wheezing in Infants (EISL) have evidenced both the great importance of these disorders and their great variability between different geographical settings and even within the same country. ${ }^{3,4}$

To date, no data have been published on wheezing in children in the province of Salamanca (Spain), with the exception of nursing infants, since Salamanca participated in the EISL ${ }^{5}$ with a cohort of 1162 children. According to the latter study, at 12 months of age, 31\% of the infants in Salamanca had experienced wheezing and $11 \%$ had already suffered three or more wheezing episodes. ${ }^{5}$ However, little is known of the subsequent evolution of these children over time. There likewise are no data on wheezing in schoolchildren in other nearby geographical settings, with the exception of the national capital Madrid, ${ }^{3}$ which presents entirely different socioeconomic characteristics.

The current notion of asthma is that it is just not a single disease but rather an umbrella term encompassing different processes with differences in terms of the underlying etiopathogenic mechanisms and evolution over time. ${ }^{6}$ Numerous genetic and environmental factors appear to be related to asthma and wheezing. ${ }^{2,7,8}$ The different phenotypes and, in recent years, the different endotypes, seek to group patients with asthma and wheezing according to certain patterns and characteristics, ${ }^{6}$ where those patients showing the same phenotype exhibit a common etiopathogenesis and evolution over time. Relating to different potential risk factors, attention has been drawn to those that manifest during pregnancy and in the postnatal period (fundamentally within the first months of life), though the true relevance of the different factors remains to be established.., 10

The present study was carried out to analyze the different wheezing phenotypes in children from Salamanca and their evolution over time, as well as their association to different perinatal risk factors.

\section{Material and methods}

\section{Study design and variables}

The longitudinal study included a cohort of 1164 children recruited during the International Study of Wheezing in Infants (EILS) in Salamanca in 2010, which included most of the primary care centers in the province. This international study, based on a validated questionnaire, ${ }^{11}$ compiled a series of risk factors referred to both pregnancy and the first year of life and that could act as risk factors for wheezing and influence its evolution over time. These variables included a paternal and maternal history of asthma and allergic disorders such as allergic rhinitis, gestational disorders (prematurity, cesarean delivery, maternal infections, placental problems, etc.), smoking exposure, paracetamol use, and domestic pets, as well as variables referred to the first year of life such as early kindergarten, siblings, atopic eczema, pneumonia, smoking parents, pets or presence of humidity or mold at home.

Between April 2018 and April 2019, a telephone questionnaire was made up with the parents of the included children, when these were between 9-10 years of age. The occurrence of wheezing in the course of life was recorded, together with the age of the child in months at the time of the first and last wheezing episode, and other clinical and epidemiological information. The questionnaire used was administered by a pediatrician and taken from the standardized questionnaire of the International Study of Asthma and Allergies in Childhood. ${ }^{3}$ The presence of wheezing was defined as a positive answer for the validated question "Has your child been diagnosed of having wheezing by a physician?"

Based on the evolution over time of wheezing, we classified the study cohort into three mutually excluding phenotypes: transient early wheezing (last episode before 3 years of age), early persistent wheezing (start before 3 years of age and persisting thereafter), and late-onset wheezing (first episode after 3 years of age). A fourth group comprised those children who had never experienced wheezing. The 3-year cut-off point was chosen because it is the most commonly used cut-off point in other phenotype studies ${ }^{12-14}$ (Figure 1).

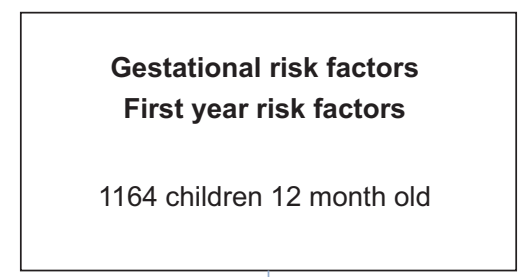

Questionnaire at 9-10 years old
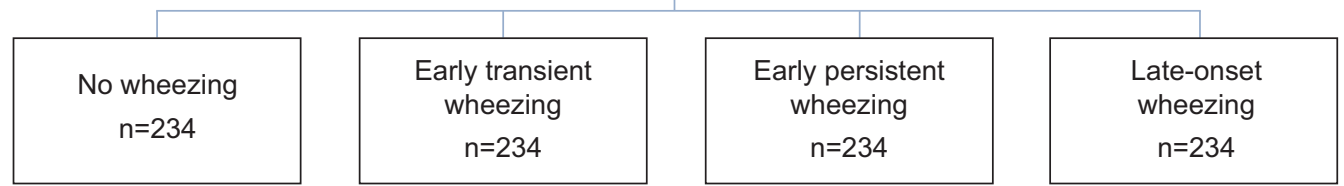

Figure 1 Study timeline and classification into phenotypes. 


\section{Statistical analysis}

Data analysis was performed using SPSS software, version 20. The Chi-square test was used to compare group percentages. Statistical significance was considered for $p<0.05$.

A bivariate analysis was made of the associations between each wheezing phenotype and the perinatal risk factors previously compiled when the children were 12 months old, taking as reference those children that had never experienced wheezing. The associations were measured based on the odds ratio (OR) and corresponding $95 \%$ confidence interval $(95 \% \mathrm{Cl})$.

A multivariate multinomial logistic regression analysis was also performed, taking wheezing phenotype as the dependent variable and the gestational and postnatal factors as independent variables. The associations were measured based on the adjusted odds ratio (aOR) and corresponding $95 \% \mathrm{Cl}$.

\section{Results}

\section{Wheezing phenotypes}

Data were collected from 531 children with a mean age of 9.79 years (standard deviation [SD] 0.41). A total of 262 were girls $(49.3 \%)$. The children were classified according to the evolution of wheezing: 169 presented transient early wheezing (31.8\%), 100 presented early persistent wheezing $(18.8 \%)$, and 28 presented late-onset wheezing (5.2\%). The remaining 234 children (44.1\%) had never experienced wheezing and represented the control group.

\section{Wheezing phenotype risk factors}

Transient early wheezing was found to be significantly associated with the following gestational risk factors (Table 1) and postnatal risk factors (Table 2 ) in the univariate analysis: cesarian section (OR 1.64), the existence of older siblings (OR 2.02), kindergarten (OR 1.55), pneumonia in the first year of life (OR 2.51), atopic eczema in the first year of life (OR 2.53), and a smoking father (OR 1.66). Exclusive breastfeeding for 3 months or more was identified as a protective factor (OR 0.64).

The multinomial analysis (Tables 3 and 4) identified the following as independent risk factors for transient early wheezing: the cesarian birth (aOR1.69), the existence of older siblings (aOR 1.95), kindergarten in the first year of life (aOR 1.61), presence of eczema in the first year (aOR 2.53), maternal eczema (aOR 2.80), and a smoking father (aOR 1.66).

Early persistent wheezing was associated with several gestational risk factors. Specifically, prematurity was three times more common (18\% versus $6.4 \%$ ) among the children with persistent wheezing than in the controls (OR 3.20), in the same way as cesarian section (OR 1.63), placental disorders during pregnancy (OR 3.60), premature rupture of membranes (OR 2.49), and paracetamol use more than once a month (OR 1.9). Several postnatal variables were identified as risk factors for early persistent wheezing phenotype: the existence of older siblings (OR 1.65) and pneumonia in the first year of life (OR 3.60). Twenty-one percent of the children with early persistent wheezing had suffered atopic eczema in the first year versus $6.4 \%$ of the controls (OR 3.88). The risk of persistent wheezing was also seen to increase with a smoking mother (OR 1.89) and a smoking father (OR 1.99). In contrast, exclusive breastfeeding for 3 months or more was identified as a protective factor against early persistent wheezing (OR 0.60), in the same way as in the case of transient wheezing.

The multinomial logistic regression analysis (Tables 3 and 4) confirmed placental problems (aOR 3.40), frequent paracetamol use during pregnancy (aOR 2.17), atopic eczema in the first year (aOR 3.21), and a smoking father (aOR 1.85) as independent risk factors associated with early persistent wheezing.

Late-onset wheezing was associated with the male gender (OR 2.72). Although all the wheezing phenotypes were more frequent in males, statistical significance was only reached in the case of late-onset wheezing. Maternal history of allergic disease in the form of both rhinitis (OR 2.61) and maternal eczema (OR 3.73) was also identified as a risk factor.

In the multinomial analysis, the male gender was maintained as an independent risk factor (aOR 3.27) associated with late-onset wheezing.

\section{Discussion}

Wheezing is extremely common in childhood, though it is not easy to determine which of the affected children will go on to develop asthma. ${ }^{15}$ Attempts have been made to group wheezing into different phenotypes associated with different risk factors, implying the existence of different underlying etiopathogenic mechanisms. Large population-based and cohort studies have contributed much information about risk factors associated with the different wheezing phenotypes. ${ }^{16-18}$

In the present study, we classified a cohort of children into three phenotypes according to the evolution of wheezing over time, and selected the age of 3 years as the cut-off point, in the same way as given by Martinez et al. ${ }^{12}$ in the Tucson cohort, to differentiate between preschool infants in which wheezing is often associated to banal respiratory conditions and children of school age. ${ }^{2,15}$

\section{Transient early wheezing}

Approximately one-third of the children in our study experienced wheezing only during the first 3 years of life - this being consistent with the observations in both other parts of Spain ${ }^{14}$ and elsewhere in the world. ${ }^{2,4}$

In our series, the identified risk factors of transient early wheezing were especially respiratory infections in the first year of life and their facilitating factors such as the existence of older siblings and early kindergarten, in coincidence with the findings of other authors. ${ }^{13,18-20}$ Pneumonia in the first year of life was found to be a risk factor for this wheezing phenotype.

A predisposition to developing atopic conditions manifesting as eczema in the first year of life and a maternal history of atopic dermatitis were also risk factors of transient 
Table 1 Univariate regression analysis showing the association between patient gender, family history, and gestational factors and the different wheezing phenotypes.

\begin{tabular}{|c|c|c|c|c|}
\hline Variable & $\begin{array}{l}\text { No wheezing } \\
(n=234,44.1 \%)\end{array}$ & $\begin{array}{l}\text { Early transient wheezing } \\
\qquad(\mathrm{n}=169,31.8 \%)\end{array}$ & $\begin{array}{l}\text { Early persistent wheezing } \\
\qquad(\mathrm{n}=100,18.8 \%)\end{array}$ & $\begin{array}{l}\text { Late-onset wheezing } \\
\qquad(\mathrm{n}=28,5.3 \%)\end{array}$ \\
\hline \multicolumn{5}{|l|}{ Male gender } \\
\hline Frequency & $47.9 \%$ & $48.5 \%$ & $55 \%$ & $71.4 \%$ \\
\hline OR $(95 \% \mathrm{Cl})$ & & $1.03(0.69-1.53)$ & $1.33(0.83-2.33)$ & $2.72(1.15-6.43)$ \\
\hline \multicolumn{5}{|c|}{ Maternal asthma } \\
\hline Frequency & $6 \%$ & $5.3 \%$ & $7 \%$ & $14.3 \%$ \\
\hline OR (95\% Cl) & & $0.88(0.37-2.01)$ & $1.18(0.46-3.03)$ & $2.62(0.80-8.59)$ \\
\hline \multicolumn{5}{|c|}{ Maternal rhinitis } \\
\hline Frequency & $15.4 \%$ & $13 \%$ & $20 \%$ & $32.1 \%$ \\
\hline OR $(95 \% \mathrm{Cl})$ & & $0.82(0.46-1.46)$ & $1.36(0.75-2.52)$ & 2.61 (1.09-6.21) \\
\hline \multicolumn{5}{|c|}{ Maternal eczema } \\
\hline Frequency & $4.3 \%$ & $10.7 \%$ & $8 \%$ & $14.3 \%$ \\
\hline OR (95\% Cl) & & 2.67 (1.20-5.94) & $1.95(0.75-5.10)$ & $3.73(1.09-12.82)$ \\
\hline \multicolumn{5}{|c|}{ Paternal asthma } \\
\hline Frequency & $3.4 \%$ & $4.7 \%$ & $3 \%$ & $3.6 \%$ \\
\hline OR $(95 \% \mathrm{Cl})$ & & $1.40(0.52-3.82)$ & $0.87(0.23-3.36)$ & $1.05(0.13-8.69)$ \\
\hline \multicolumn{5}{|c|}{ Paternal rhinitis } \\
\hline Frequency & $13.2 \%$ & $17.2 \%$ & $20 \%$ & $14.3 \%$ \\
\hline OR $(95 \% \mathrm{Cl})$ & & $1.36(0.78-2.35)$ & $1.64(0.89-3.04)$ & $1.09(0.36-3.63)$ \\
\hline \multicolumn{5}{|c|}{ Paternal eczema } \\
\hline Frequency & $3.4 \%$ & $5.9 \%$ & $7.1 \%$ & $3.6 \%$ \\
\hline OR $(95 \% \mathrm{Cl})$ & & $1.78(0.69-4.60)$ & $2.15(0.76-6.01)$ & $1.05(0.13-8.69)$ \\
\hline \multicolumn{5}{|l|}{ Prematurity } \\
\hline Frequency & $6.4 \%$ & $8.3 \%$ & $18 \%$ & $7.1 \%$ \\
\hline OR $(95 \% \mathrm{Cl})$ & & $1.32(0.62-2.81)$ & $3.20(1.54-6.65)$ & $1.12(0.24-5.19)$ \\
\hline \multicolumn{5}{|c|}{ Caesarean section } \\
\hline Frequency & $31.6 \%$ & $43.2 \%$ & $43 \%$ & $39.3 \%$ \\
\hline OR (95\%Cl) & & $1.64(1.09-2.48)$ & $1.63(1.01-2.64)$ & $1.40(0.62-3.14)$ \\
\hline \multicolumn{5}{|c|}{ Placental problems } \\
\hline Frequency & $3 \%$ & $6.5 \%$ & $10 \%$ & $3.6 \%$ \\
\hline OR $(95 \% \mathrm{Cl})$ & & $2.26(0.86-5.95)$ & $3.60(1.33-9.76)$ & $1.20(0.14-10.14)$ \\
\hline \multicolumn{5}{|c|}{ Premature RM } \\
\hline Frequency & $4.3 \%$ & $5.3 \%$ & $10 \%$ & $7.1 \%$ \\
\hline OR $(95 \% \mathrm{Cl})$ & & $1.26(0.50-3.17)$ & $2.49(1.002-6.18)$ & $1.72(0.36-8.30)$ \\
\hline \multicolumn{5}{|l|}{ Infections } \\
\hline Frequency & $20.5 \%$ & $21.3 \%$ & $24 \%$ & $7.1 \%$ \\
\hline OR $(95 \% \mathrm{Cl})$ & & $1.05(0.65-1.71)$ & $1.22(0.70-2.14)$ & $0.30(0.07-1.30)$ \\
\hline \multicolumn{5}{|c|}{ Paracetamol >1/mo. } \\
\hline Frequency & $12.4 \%$ & $13 \%$ & $22 \%$ & $14.3 \%$ \\
\hline OR $(95 \% \mathrm{Cl})$ & & $1.06(0.59-1.92)$ & $1.99(1.08-3.68)$ & $1.18(0.38-3.64)$ \\
\hline \multicolumn{5}{|c|}{ Smoking in pregnancy } \\
\hline Frequency & $13.7 \%$ & $10.7 \%$ & $19 \%$ & $10.7 \%$ \\
\hline OR (95\% Cl) & & $0.75(0.41-1.39)$ & $1.48(0.79-2.76)$ & $0.76(0.22-2.66)$ \\
\hline \multicolumn{5}{|c|}{ Domestic pets in pregnancy } \\
\hline Frequency & $17.1 \%$ & $18.9 \%$ & $22 \%$ & $10.7 \%$ \\
\hline OR $(95 \% \mathrm{Cl})$ & & $1.13(0.68-1.89)$ & $1.37(0.76-2.45)$ & $0.58(0.17-2.02)$ \\
\hline
\end{tabular}

Three independent logistic regression analyses were performed of each wheezing phenotype with respect to the non-wheezing control group. The statistically significant associations $(p<0.05)$ are reported in the shaded cells. Premature RM: Premature rupture of membranes. Paracetamol $>1 /$ mo.: paracetamol use more than once a month during pregnancy. 
Table 2 Univariate regression analysis showing the association between postnatal factors and the different wheezing phenotypes.

\begin{tabular}{|c|c|c|c|c|}
\hline Variable & $\begin{array}{l}\text { No wheezing } \\
\quad(n=234)\end{array}$ & $\begin{array}{l}\text { Early transient wheezing } \\
\qquad(\mathrm{n}=169)\end{array}$ & $\begin{array}{l}\text { Early persistent wheezing } \\
\qquad(\mathrm{n}=100)\end{array}$ & $\begin{array}{l}\text { Late-onset wheezing } \\
\qquad(\mathrm{n}=28)\end{array}$ \\
\hline \multicolumn{5}{|c|}{ Presence of siblings } \\
\hline Frequency & $40.6 \%$ & $58 \%$ & $53 \%$ & $42.9 \%$ \\
\hline OR $(95 \% \mathrm{Cl})$ & & $2.02(1.35-3.02)$ & $1.65(1.03-2.64)$ & $1.10(0.50-2.42)$ \\
\hline \multicolumn{5}{|c|}{ Kindergarten } \\
\hline Frequency & $25.3 \%$ & $34.3 \%$ & $26 \%$ & $32.1 \%$ \\
\hline OR $(95 \% \mathrm{Cl})$ & & $1.55(1.01-2.39$ & $1.04(0.61-1.78)$ & $1.40(0.60-3.28)$ \\
\hline \multicolumn{5}{|l|}{ Pneumonia } \\
\hline Frequency & $0 \%$ & $8.3 \%$ & $10 \%$ & $0 \%$ \\
\hline OR $(95 \% \mathrm{Cl})$ & & $2.51(2.22-2.84)$ & $3.60(3.02-4.29)$ & \\
\hline \multicolumn{5}{|c|}{ Atopic eczema } \\
\hline Frequency & $6.4 \%$ & $14.8 \%$ & $21 \%$ & $3.6 \%$ \\
\hline OR $(95 \% \mathrm{Cl})$ & & $2.53(1.29-4.97)$ & $3.88(1.91-7.90)$ & $0.54(0.07-4.26)$ \\
\hline \multicolumn{5}{|c|}{ Smoking mother } \\
\hline Frequency & $18.5 \%$ & $18.3 \%$ & $30 \%$ & $17.9 \%$ \\
\hline OR $(95 \% \mathrm{Cl})$ & & $0.99(0.59-1.65)$ & 1.89 (1.10-3.25) & $0.96(0.35-2.67)$ \\
\hline \multicolumn{5}{|c|}{ Smoking father } \\
\hline Frequency & $24.1 \%$ & $34.5 \%$ & $38.8 \%$ & $33.3 \%$ \\
\hline OR $(95 \% \mathrm{Cl})$ & & $1.66(1.07-2.57)$ & $1.99(1.20-3.30)$ & $1.57(0.67-3.70)$ \\
\hline \multicolumn{5}{|c|}{ Domestic pets } \\
\hline Frequency & $19.7 \%$ & $18.9 \%$ & $26 \%$ & $7.1 \%$ \\
\hline OR (95\% Cl) & & $0.95(0.58-1.58)$ & $1.44(0.83-2.49)$ & $0.31(0.07-1.37)$ \\
\hline \multicolumn{5}{|c|}{ Moldiness/humidity } \\
\hline Frequency & $6 \%$ & $7.7 \%$ & $7 \%$ & $10.7 \%$ \\
\hline OR $(95 \% \mathrm{Cl})$ & & $1.30(0.60-2.85)$ & $1.18(0.46-3.01)$ & $1.88(0.51-6.98)$ \\
\hline \multicolumn{5}{|c|}{$\mathrm{EBF}>3$ months } \\
\hline Frequency & $66.2 \%$ & $55.6 \%$ & $54 \%$ & $50 \%$ \\
\hline OR (95\% Cl) & & $0.64(0.43-0.96)$ & $0.60(0.37-0.97)$ & $0.51(0.23-1.12)$ \\
\hline
\end{tabular}

Three independent logistic regression analyses were performed of each wheezing phenotype with respect to the nonwheezing control group. The risk factors are referred to the first year of life. The statistically significant associations $(p<0.05)$ are reported in the shaded cells.

EBF >3 months: exclusive breastfeeding for at least 3 months.

early wheezing in our series. These results may seem unexpected, since atopy, as the main risk factor of asthma, ${ }^{21}$ would appear to be associated with persistent wheezing and of late-onset, but not to transient early wheezing, as in the Tucson cohort. ${ }^{12}$ However, in other studies, ${ }^{18,22} \mathrm{a}$ family history of allergy was associated with all wheezing phenotypes. A possible explanation could be that children with transient early wheezing are actually allergic individuals and at risk of suffering asthma in adult life. This could be accounted for by diminished lung function from birth, as described by Martinez et al..$^{2}$ and confirmed by different long-term follow-up studies involving children with transient early wheezing. ${ }^{23,24}$

In our study, a smoking father was found to be a significant risk factor for transient early wheezing, in coincidence with the observations of other authors. ${ }^{25}$ In this regard, it may be hypothesized that during pregnancy the fetus may have been exposed to tobacco smoke through the mother as a passive smoker. A systematic review has found both prenatal and postnatal smoking exposure to be related to wheezing and harmful respiratory effects for the infant, as well as to low birth weight. ${ }^{26}$ Investigations in animals have shown tobacco smoke to act at the intrauterine level, interfering with fetal growth and giving rise to pulmonary hypoplasia. ${ }^{27}$

The cesarian section was associated with this wheezing phenotype both in our study and in other publications. ${ }^{22}$ By avoiding delivery through the birth canal, a cesarian section may cause alterations of the intestinal microbiome of the newborn infant and have future repercussions upon the immune response. However, prospective studies have found no relationship between cesarian section and asthma. ${ }^{7,9}$

According to our data, exclusive breastfeeding for at least 3 months acts as a protective factor against both transient and persistent wheezing. This may be explained by the important protective effect of breastfeeding against respiratory infections in small infants. ${ }^{20,28}$

\section{Early persistent wheezing}

In our series, the identified risk factors of early persistent wheezing included different gestational disorders 
Table 3 Multinomial logistic regression analysis showing the association between patient gender, family history, and gestational factors and the different wheezing phenotypes.

\begin{tabular}{|c|c|c|c|c|}
\hline Variable & $\begin{array}{l}\text { No wheezing } \\
\text { (control) }\end{array}$ & $\begin{array}{l}\text { Early transient wheezing } \\
\qquad(\mathrm{n}=169,31.8 \%)\end{array}$ & $\begin{array}{l}\text { Early persistent wheezing } \\
\qquad(\mathrm{n}=100,18.8 \%)\end{array}$ & $\begin{array}{l}\text { Late-onset wheezing } \\
\qquad(\mathrm{n}=28,5.3 \%)\end{array}$ \\
\hline \multicolumn{5}{|l|}{ Male gender } \\
\hline aOR $(95 \% \mathrm{Cl})$ & & $1.10(0.73-5.79)$ & $1.46(0.88-2.40)$ & $3.27(1.30-8.24)$ \\
\hline \multicolumn{5}{|l|}{ Maternal asthma } \\
\hline aOR $(95 \% \mathrm{Cl})$ & & $0.93(0.36-2.88)$ & $0.99(0.35-2.86)$ & $2.31(0.58-9.13)$ \\
\hline \multicolumn{5}{|l|}{ Maternal rhinitis } \\
\hline aOR $(95 \% \mathrm{Cl})$ & & $0.80(0.42-1.72)$ & $1.29(0.64-2.60)$ & $2.22(0.82-5.98)$ \\
\hline \multicolumn{5}{|l|}{ Maternal eczema } \\
\hline aOR $(95 \% \mathrm{Cl})$ & & $2.80(1.22-2.12)$ & $1.83(0.67-4.98)$ & $3.50(0.91-13.42)$ \\
\hline \multicolumn{5}{|l|}{ Paternal asthma } \\
\hline aOR $(95 \% \mathrm{Cl})$ & & 0.77 (0.49-1.41) & $0.93(0.22-3.92)$ & 2.27 (0.24-21.17) \\
\hline \multicolumn{5}{|l|}{ Paternal rhinitis } \\
\hline aOR $(95 \% \mathrm{Cl})$ & & $1.31(0.72-1.92)$ & $1.37(0.68-2.73)$ & $0.92(0.27-3.18)$ \\
\hline \multicolumn{5}{|l|}{ Paternal eczema } \\
\hline aOR $(95 \% \mathrm{Cl})$ & & $1.72(0.64-4.64)$ & $2.11(0.67-6.66)$ & $0.88(0.09-8.29)$ \\
\hline \multicolumn{5}{|l|}{ Prematurity } \\
\hline aOR $(95 \% \mathrm{Cl})$ & & $0.93(0.40-2.17)$ & $2.12(0.92-4.90)$ & $0.98(0.18-5.44)$ \\
\hline \multicolumn{5}{|l|}{ Cesarean section } \\
\hline aOR $(95 \% \mathrm{Cl})$ & & 1.69 (1.09-2.61) & $1.33(0.78-2.26)$ & $1.68(0.70-4.04)$ \\
\hline \multicolumn{5}{|l|}{ Placental problems } \\
\hline aOR $(95 \% \mathrm{Cl})$ & & $2.14(0.79-5.79)$ & 3.40 (1.16-9.96) & $1.79(0.19-16.31)$ \\
\hline \multicolumn{5}{|l|}{ Premature RM } \\
\hline aOR $(95 \% \mathrm{Cl})$ & & $1.04(0.37-2.08)$ & $1.73(0.62-4.78)$ & $1.26(0.22-7.25)$ \\
\hline \multicolumn{5}{|l|}{ Infections } \\
\hline aOR $(95 \% \mathrm{Cl})$ & & $1.03(0.61-1.72)$ & $0.98(0.53-1.80)$ & $0.28(0.06-1.29)$ \\
\hline \multicolumn{5}{|l|}{ Paracetamol >1/mo. } \\
\hline aOR $(95 \% \mathrm{Cl})$ & & $1.16(0.63-2.12)$ & $2.17(1.14-4.12)$ & $1.10(0.34-3.59)$ \\
\hline \multicolumn{5}{|l|}{ Smoking in pregnancy } \\
\hline aOR $(95 \% \mathrm{Cl})$ & & $0.74(0.39-1.41)$ & $1.47(0.74-2.89)$ & $1.08(0.29-4.08)$ \\
\hline \multicolumn{5}{|l|}{ Domestic pets in pregnancy } \\
\hline aOR $(95 \% \mathrm{Cl})$ & & $1.12(0.65-1.93)$ & $1.39(0.74-2.59)$ & $0.80(0.22-2.93)$ \\
\hline
\end{tabular}

Multinomial logistic regression analysis, with "wheezing phenotypes" as dependent variable and genetic and gestational risk factors as independent variables. The adjusted odds ratio (aOR) and corresponding $95 \%$ confidence interval are reported. The statistically significant associations $(p<0.05)$ are reported in the shaded cells.

Premature RM: Premature rupture of membranes. Paracetamol $>1 /$ mo.: paracetamol use more than once a month during pregnancy.

(placental problems, frequent use of paracetamol during pregnancy, prematurity, premature rupture of membranes, and cesarian section), in coincidence with the observations of other authors. ${ }^{22} \mathrm{~A}$ more solid association has been established between asthmatic symptoms in children and maternal infections during pregnancy, ${ }^{29}$ and the variable "paracetamol use" could be related to this.

The presence of atopic eczema in the first year of life was identified as a risk factor for early persistent wheezing in our patients: one out of every five children with early persistent wheezing presented atopic eczema in the first year of life (versus 6\% of the children without wheezing). Other phenotype studies corroborate the relationship between atopic symptoms and persistent wheezing. ${ }^{12,20,22}$

Although infections in early childhood are fundamentally related to transient early wheezing, in our study exposure to infections (pneumonia, the existence of older siblings) also increased the risk of persistent wheezing, in coincidence with the observations of other authors. ${ }^{22}$ There is evidence that early respiratory infections, particularly when severe, are associated with recurrent wheezing and asthma. ${ }^{30,31}$ It has been suggested that infections due to rhinovirus or respiratory syncytial virus may be related to diminished lung function, which in turn would increase the risk of asthma and persistent wheezing, though it remains to be determined whether this is a cause or a consequence of the former. ${ }^{32}$

Smoking on the part of the father and mother in the first year of life of the infant was found to be a risk factor for persistent wheezing, in coincidence with the observations of other authors. ${ }^{12,13,18,20}$

In our study, exclusive breastfeeding for at least 3 months exerted a protective effect against persistent wheezing. The association between breastfeeding and asthma has been the subject of much debate, though there is abundant evidence in the literature on the 
Table 4 Multinomial logistic regression analysis showing the association between the postnatal risk factors and the different wheezing phenotypes.

\begin{tabular}{|c|c|c|c|c|}
\hline Variable & $\begin{array}{l}\text { No wheezing } \\
\text { (control) }\end{array}$ & $\begin{array}{l}\text { Early transient wheezing } \\
\qquad(\mathrm{n}=169)\end{array}$ & $\begin{array}{l}\text { Early persistent wheezing } \\
\qquad(\mathrm{n}=100)\end{array}$ & $\begin{array}{l}\text { Late-onset wheezing } \\
\qquad(\mathrm{n}=28)\end{array}$ \\
\hline \multicolumn{5}{|c|}{ Presence of siblings } \\
\hline aOR $(95 \% \mathrm{Cl})$ & & $1.95(1.28-2.97)$ & $1.47(0.89-2.43)$ & $0.96(0.42-2.20)$ \\
\hline \multicolumn{5}{|l|}{ Kindergarten } \\
\hline aOR (95\% Cl) & & $1.61(1.02-2.56)$ & $1.20(0.68-2.12)$ & $1.48(0.62-3.54)$ \\
\hline \multicolumn{5}{|l|}{ Atopic eczema } \\
\hline aOR $(95 \% \mathrm{Cl})$ & & $2.23(1.09-4.57)$ & $3.21(1.52-6.79)$ & $0.58(0.07-4.64)$ \\
\hline \multicolumn{5}{|c|}{ Smoking mother } \\
\hline aOR (95\% Cl) & & $0.68(0.38-1.21)$ & $1.22(0.66-2.26)$ & $0.92(0.30-2.84)$ \\
\hline \multicolumn{5}{|l|}{ Smoking father } \\
\hline aOR $(95 \% \mathrm{Cl})$ & & $1.85(1.15-2.99)$ & $1.85(1.07-3.21)$ & $1.52(0.60-3.83)$ \\
\hline \multicolumn{5}{|l|}{ Domestic pets } \\
\hline aOR $(95 \% \mathrm{Cl})$ & & $0.93(0.55-1.57)$ & $1.31(0.73-2.34)$ & $0.31(0.07-1.36)$ \\
\hline \multicolumn{5}{|c|}{ Moldiness/humidity } \\
\hline aOR $(95 \% \mathrm{Cl})$ & & $1.31(0.57-3.03)$ & $0.96(0.35-2.64)$ & $2.15(0.56-8.27)$ \\
\hline \multicolumn{5}{|l|}{ EBF $>3$ months } \\
\hline aOR (95\% Cl) & & $0.80(0.52-1.24)$ & $0.76(0.46-1.27)$ & $0.55(0.24-1.26)$ \\
\hline
\end{tabular}

Multinomial logistic regression analysis, with “wheezing phenotypes” as dependent variable and genetic and gestational risk factors as independent variables. The adjusted odds ratio (aOR) and corresponding $95 \%$ confidence interval are reported. The statistically significant associations $(p<0.05)$ are reported in the shaded cells. The risk factors are referred to first year of life.

EBF >3 months: exclusive breastfeeding for at least 3 months. The independent variable "pneumonia in the first year could not be entered in the analysis due to the presence of values of " 0 " in some phenotypes.

ability of breastfeeding to extend its protective effect against wheezing and asthma beyond the first few years of life. ${ }^{16,33,34}$ A possible explanation for this could be the immune-modulating effect of breastfeeding and its action upon the intestinal microbiota, which in turn largely conditions atopic predisposition towards atopic disorders. ${ }^{35,36}$

\section{Late-onset wheezing}

Children with late-onset wheezing have been traditionally regarded as "true asthmatics", ${ }^{37}$ i.e., children with a predisposition towards atopic disorders who have not experienced early wheezing conditioned by respiratory infections and who develop asthmatic symptoms outside this influencing viral infection period. Martinez et al. ${ }^{12}$ reported the main risk factor for this type of late-onset wheezing to be a personal as well as maternal predisposition towards atopic disorders. On the other hand, follow-up of the Tucson cohort evidenced that the risk of progression towards asthma is not only associated with the late-onset wheezing phenotype but also with the early persistent wheezing phenotype. ${ }^{24}$ In our series, the significant risk factor for late-onset wheezing was found to be maternal allergic disease (rhinitis and allergic dermatitis), in concordance with the data from other studies. ${ }^{18,22}$

In our study, the male gender predominated in both the persistent phenotype and in the late-onset phenotype, though statistical significance was only observed in this latter case, in coincidence with the results of other studies. ${ }^{12,13}$

\section{Limitations and strengths}

An important limitation of our study is the fact that the information on wheezing in the children was supplied by the parents on a retrospective basis - with the resulting memory bias. We believe that this effect may be reduced in part by the fact that the information was collected by an experienced pediatrician and not from a self-administered parent questionnaire. On the other hand, we suffered an important loss of sample size since the recruitment of the cohort, because of the 9 years that had elapsed.

The strengths of our study include the fact that there are practically no studies on phenotypes and risk factors in the Spanish population, despite the broad geographical differences in asthma and wheezing between territories. Likewise, the perinatal variables were recorded when the infants were 12 months old, which greatly reduces memory bias, and the association between the variables and the phenotypes was established on a prospective basis. It should be mentioned that some of the possible incongruences between the univariate and the multivariate regression analysis in the late-onset wheezing phenotype could be due to the fact that the number of patients with this particular phenotype was limited.

\section{Conclusions}

We consider it is very important to be aware of the extremely high frequency of wheezing in children, and to know its risk factors, in order to be able to act upon 
those factors that are avoidable. Although most patients with early wheezing evolve satisfactorily, the disorder has also been associated with asthma of onset in adult life. ${ }^{24}$ Therefore, it would be of great interest to reduce the number of affected children as far as possible, not only in view of the impact of the disorder upon the quality of life of the patients and their parents but also of the future health repercussions. Possible measures in this respect could be the avoidance of smoking both during pregnancy and in the first year of life of the infant, the avoidance of early kindergarten as far as possible, and the encouragement of breastfeeding. Lastly, it must be emphasized that observational studies are unable to establish causal relationships but do pave the way to future research.

\section{References}

1. Mallol J, García-Marcos L, Solé D. International prevalence of recurrent wheezing during the first year of life: variability, treatment patterns and use of health resources. Thorax. 2010;65:1004-1009. https://doi.org/10.1136/thx.2009.115188

2. Wright AL. Epidemiology of asthma and recurrent wheeze in childhood. Clin Rev Allergy Immunol. 2002;22:33-44. https:// doi.org/10.1007/s12016-002-0004-z

3. Carvajal-Urueña I, García-Marcos L, Busquets-Monge R, Morales Suárez-Varela M, García de Andoin N, BatllesGarrido J, et al. [Geographic variation in the prevalence of asthma symptoms in Spanish children and adolescents. International Study of Asthma and Allergies in Childhood (ISAAC) Phase 3, Spain]. Arch Bronconeumol. 2005;41:659-666. https://doi.org/10.1016/S1579-2129(06)60333-9; https://doi. org/10.1016/S0300-2896(05)70721-3

4. Garcia-Marcos L, Mallol J, Solé D,Brand PL. International study of wheezing in infants: risk factors in affluent and non-affluent countries during the first year of life. Pediatr Allergy Immunol. 2010;21:878-888. https://doi. org/10.1111/j.1399-3038.2010.01035.x

5. Pellegrini-Belinchón J, Lorente-Toledano F, Galindo-Villardón P, González-Carvajal I, Martín-Martín J, Mallol J, et al. Factors associated to recurrent wheezing in infants under one year of age in the province of Salamanca, Spain: Is intervention possible? A predictive model. Allergol Immunopathol (Madr). 2016;44:393-399. https://doi.org/10.1016/j.aller.2015.09.001

6. Licari A, Castagnoli R, Brambilla I, Marseglia A, Tosca MA, Marseglia GL, et al. Asthma endotyping and biomarkers in childhood asthma. Pediatr Allergy Immunol Pulmonol. 2018;31:44-55. https://doi.org/10.1089/ped.2018.0886

7. Kim A, Lim G, Oh I, Kim Y, Lee T, Lee J. Perinatal factors and the development of childhood asthma. Ann Allergy, Asthma Immunol. 2018;120:292-299. https://doi.org/10.1016/j. anai.2017.12.009

8. Malaeb D, Hallit S, Sacre H, Hallit R, Salameh P. Factors associated with wheezing among Lebanese children: results of a cross-sectional study. Allergol Immunopathol (Madr). 2020;48:523-529. https://doi.org/10.1016/j.aller.2020.02.003

9. Kashanian M, Mohtashami SS, Bemanian MH, Moosavi SA, Moradi Lakeh M. Evaluation of the associations between childhood asthma and prenatal and perinatal factors. Int J Gynecol Obstet. 2017;137:290-294. https://doi.org/10.1002/ijgo.12141

10. Hallit S, Leynaert B, Delmas MC, Rocchi S, De Blic J, Marguet $\mathrm{C}$, et al. Wheezing phenotypes and risk factors in early life: the ELFE cohort. PLoS One. 2018;13:e0196711. https://doi.org/10.1371/journal.pone.0196711

11. Mallol J, García-Marcos L, Aguirre V, Martinez-Torres A, PerezFernandez V, Gallardo A, et al. The international study of wheezing in infants: questionnaire validation. Int Arch Allergy Immunol. 2007;144:44-50. https://doi.org/10.1159/000102613

12. Martinez FD, Wright AL, Taussig LM, Holberg CJ, Halonen M, Morgan WJ. Asthma and wheezing in the first six years of life. N Engl J Med. 1995;332:133-138. https://doi.org/10.1056/ NEJM199501193320301

13. De Sario M, Domenicantonio R Di, Corbo G, Forastiere F, Pistelli R, Rusconi F, et al. Characteristics of early transient, persistent, and late onset wheezers at 9 to 11 years of age. J Asthma. 2006;43:633-638. https://doi. org/10.1080/02770900600878974

14. Garcinuño AC, Gandarillas IM, Cobo Ruisánchez Á, Pérez Candás I, Díaz Estrada E, Yáñez Meana B, et al. Early patterns of wheezing in asthmatic and nonasthmatic children. Eur Respir J. 2013;42:1020-1028. https://doi. org/10.1183/09031936.00148712

15. Piippo-Savolainen E, Korppi M. Wheezy babies - wheezy adults? Review on long-term outcome until adulthood after early childhood wheezing. Acta Paediat Int J Paediatr. 2008;97:5-11. https://doi.org/10.1111/j.1651-2227.2007.00558.x

16. Kim H, Sitarik AR, Woodcroft K, Jhonson CC, Zoratti E. Birth mode, breastfeeding, pet exposure, and antibiotic use: associations with the gut microbiome and sensitization in children. Curr Allergy Asthma Rep. 2019;19(4):22. https://doi. org/10.1007/s11882-019-0851-9

17. De Luca G, Olivieri F, Melotti G, Aiello G, Lubrano L, Boner AL. Fetal and early postnatal life roots of asthma. J Matern Fetal Neonatal Med. 2010;23(Suppl 3):80-83. https://doi.org/10.310 9/14767058.2010.509931

18. Caudri D, Savenije OE, Smit HA, Postma DS, Koppelman GH, Wijga $\mathrm{AH}$, et al. Perinatal risk factors for wheezing phenotypes in the first 8 years of life. Clin Exp Allergy. 2013;43:13951405. https://doi.org/10.1111/cea.12173

19. Marbury MC, Maldonado G, Waller L. Lower respiratory illness, recurrent wheezing, and day care attendance. Am J Respir Crit Care Med. 1997;155:156-161. https://doi.org/10.1164/ ajrccm.155.1.9001305

20. Rusconi F, Galassi C, Corbo GM, Forastiere F, Biggeri A, Ciccone G, et al. Risk factors for early, persistent, and late-onset wheezing in young children. Am J Respir Crit Care Med. 1999;160:16171622. https://doi.org/10.1164/ajrccm.160.5.9811002

21. Sly PD, Boner AL, Björksten B, Bush A, Custovic A, Eigenmann PA, et al. Early identification of atopy in the prediction of persistent asthma in children. Lancet. 2008;372:11001106. https://doi.org/10.1016/S0140-6736(08)61451-8

22. Midodzi WK, Rowe BH, Majaesic CM, Saunders LD, Senthilselvan A. Predictors for wheezing phenotypes in the first decade of life. Respirology. 2008;13:537-545. https://doi. org/10.1111/j.1440-1843.2008.01284.x

23. Morgan WJ, Stern DA, Sherrill DL, Guerra S, Holberg CJ, Guilbert TW, et al. Outcome of asthma and wheezing in the first 6 years of life follow-up through adolescence. Am J Respir Crit Care Med. 2005;172:1253-1258. https://doi.org/10.1164/ rccm.200504-5250C

24. Stern DA, Morgan WJ, Halonen M, Wright AL, Martinez FD. Wheezing and bronchial hyper-responsiveness in early childhood as predictors of newly diagnosed asthma in early adulthood: a longitudinal birth-cohort study. Lancet. 2008;372:1058-1064. https://doi.org/10.1016/S0140-6736(08)61447-6

25. Midodzi WK, Rowe BH, Majaesic CM, Saunders LD, Senthilselvan A. Early life factors associated with incidence of physician-diagnosed asthma in preschool children: results from the Canadian early childhood development cohort study. J Asthma. 2010;47:7-13. https://doi. org $/ 10.3109 / 02770900903380996$

26. DiFranza JR, Aligne CA, Weitzman M. Prenatal and postnatal environmental tobacco smoke exposure and children's health. Pediatrics. 2004;113:1007-1015. PMID: 15060193. 
27. Collins MH, Moessinger AC, Kleinerman J, Bassi J, Rosso P, Collins AM, et al. Fetal lung hypoplasia associated with maternal smoking: a morphometric analysis. Pediatr Res. 1985;19:408412. https://doi.org/10.1203/00006450-198519040-00018

28. Miliku K, Azad MB. Breastfeeding and the developmental origins of asthma: current evidence, possible mechanisms, and future research priorities. Nutrients. 2018;10(8):995. https:// doi.org/10.3390/nu10080995

29. Calvani M, Alessandri C, Sopo SM, Panetta V, Tripodi S, Torre A, et al. Infectious and uterus related complications during pregnancy and development of atopic and nonatopic asthma in children. Allergy Eur J Allergy Clin Immunol. 2004;59:99-106. https://doi.org/10.1046/j.1398-9995.2003.00338.x

30. Bacharier LB, Cohen R, Schweiger T, Yin-Declue H, Christie C, Zheng $\mathrm{J}$, et al. Determinants of asthma after severe respiratory syncytial virus bronchiolitis. J Allergy Clin Immunol. 130. Epub ahead of print 2012. https://doi.org/10.1016/j. jaci.2012.02.010

31. Régnier SA, Huels J. Association between respiratory syncytial virus hospitalizations in infants and respiratory sequelae: systematic review and meta-analysis. Pediatr Infect Dis J. 2013;32:820-826. https://doi.org/10.1097/ INF.0b013e31829061e8

32. Guilbert TW, Singh AM, Danov Z, Evans MD, Jackson DJ, Burton $R$, et al. Decreased lung function after preschool wheezing rhinovirus illnesses in children at risk to develop asthma. J Allergy Clin Immunol. 2011;128:532-8.e1-532-8.e10. https://doi.org/10.1016/j.jaci.2011.06.037

33. Lodge CJ, Tan DJ, Lau MXZ, Dai X, Tham R, Lowe AJ, et al. Breastfeeding and asthma and allergies: a systematic review and meta-analysis. Acta Paediatr. 2015;104:38-53. https://doi. org/10.1111/apa.13132

34. Guilbert TW, Stern DA, Morgan WJ, Martinez FD, Wright AL. Effect of breastfeeding on lung function in childhood and modulation by maternal asthma and atopy. Am J Respir Crit Care Med. 2007;176:843-848. https://doi.org/10.1164/ rccm.200610-15070C

35. Oddy WH. Breastfeeding, childhood asthma, and allergic disease. Ann Nutr Metab. 2017;70:26-36. https://doi. org/10.1159/000457920

36. Lee-Sarwar KA, Kelly RS, Lasky-Su J, Zeiger RS, O'Connor GT, Sandel MT, et al. Integrative analysis of the intestinal metabolome of childhood asthma. J Allergy Clin Immunol. 2019;144:442-454. https://doi.org/10.1016/j.jaci.2019.02.032

37. Stein RT, Holberg CJ, Morgan WJ, Wright AL, Lombardi E, Taussing L, et al. Peak flow variability, methacholine responsiveness and atopy as markers for detecting different wheezing phenotypes in childhood. Thorax. 1997;52:946-952. https://doi.org/10.1136/thx.52.11.946 